DOI 10.37882/2223-2982.2020.12-2.07

\title{
ОСОБЕННОСТИ ОБУЧЕНИЯ СТУДЕНТОВ-ИНОСТРАНЦЕВ МОНОЛОГИЧЕСКОМУ ВЫСКАЗЫВАНИЮ НА МАТЕРИАЛЕ ТЕКСТОВ ПО СПЕЦИАЛЬНОСТИ
}

\section{FEATURES OF TEACHING FOREIGN STUDENTS A MONOLOGUE ON THE BASIS OF TEXTS IN THE SPECIALTY \\ O. Gadzhimirzoeva}

Summary: The article deals with the linguistic characteristics of oral monological speech and aspects of the formation of skills and abilities of monological utterance based on texts of scientific content Based on the analysis, the technology of teaching foreign students to monologue on scientific and professional topics in Russian is proposed.

Keywords: monologue speech; utterance; goal; level; stage; skill; principle; scientific style of speech; language training specialty.
K онечной целью обучения иностранных учащихся русскому языку является неподготовленная спонтанная речь на научные темы, т.е. умение строить собственное высказывание. Для этого необходимо: а) научить студентов выбирать тему высказывания и реализовать ее в адекватной языковой форме; б) научить объединять отдельные коммуникативно завершенные высказывания в единое структурно-семантическое целое на уровне текста. Промежуточной целью обучения является развитие умений воспроизводить и интерпретировать информацию, извлеченную из текста, строить высказывание по аналогии с изученным текстом и, поскольку воспроизведение письменных текстов учебников, учебных пособий и лекционных материалов составляет одну из главных форм общения и, следовательно, обучения иностранных студентов избранной специальности. Обучение речи с заранее «заданным» содержанием является одной из задач обучения студентов-иностранцев на подготовительном факультете.

Для воспроизведения прочитанного или прослушанного сообщения необходимо понять (осмыслить), запомнить и только потом воспроизвести содержащуюся в этом сообщении информацию, передав ее в соответствии с нормами данного языка и стиля. Из психологии известно, что удержание и передача речевого сообщения зависят от направленности внимания, объема и характера передаваемой информации и повторного восприятия текста [3,4]. Воспроизведение сообщения может быть большей или меньшей степени свернутости, пол-
Гаджимирзоева Олеся Сабировна

К.филол.н., дочент, ФГБОУ ВО «Дагестанский государственный университет»

olesya_sab@mail.ru

Аннотация: В статье рассматриваются лингвистические характеристики устной монологической речи и аспекты формирования навыков и умений монологического высказывания на основе текстов научного содержания.

На основе проведенного анализа предлагается технология обучения студентов-иностранцев монологическому высказыванию на научные и профессиональные темы на русском языке.

Ключевые слова: монологическая речь, высказывание, цель, уровень, этап, умение, принцип, научный стиль речи, обучение языку специальности.

ноты, точности и последовательности в зависимости от коммуникативного задания, что, в свою очередь, предопределяет необходимость сплошного или выборочного запоминания. Механизмы запоминания, сохранения и воспроизведения выступают как неразрывное целое в процессе переработки предъявленной информации. Это единство проявляется в их взаимообусловленности: структура процесса запоминания определяет структуру процесса воспроизведения.

Известно, что установка на запоминание не может сама по себе обеспечить высокую продуктивность этого процесса, если учащийся не владеет теми или иными способами преобразования материала. Результаты запоминания, а следовательно, и воспроизведение предъявленной информации во многом зависят от степени сформированности способов логической обработки материала, от степени сформированности некоторых речемыслительных операций.

При воспроизведении принятого сообщения, как отмечает А.А. Смирнов, могут иметь место следующие речемыслительные операции, свидетельствующие о творческом характере этого процесса:

1. обобщение того, что дано в конкретной, развернутой, форме;

2. конкретизация и детализация того, что дано в более общем или сжатом виде;

3. замена одного содержания другим, равнозначным по смыслу, а также по степени общности и 
детализации;

4. смещение или перемещение отдельных частей;

5. объединение того, что дано отдельно друг от друга, разъединение того, что в оригинале связано между собой;

6. дополнения, выходящие за пределы сообщения

Именно эта мыслительная деятельность, в ее самых разнообразных и сложных проявлениях, и составляет психологическое ядро воспроизведения [8, с.158].

На основании вышеизложенного можно сделать вывод, что вос-произведению как особому активному сознательному речевому процессу, представляющему собой итог сложной психической деятельности, надо обучать специально, и что целесообразны специальные упражнения для развития у учащихся перечисленных выше речемыслительных операций.

При порождении подготовленного устного монологического высказывания иностранные учащиеся опираются на заданное текстом содержание. С точки зрения языкового материала и структурно- композиционного оформления высказывание также подготовлено. При обучении устной речи, могут быть использованы упражнения с опорой на формальные признаки (ключевые слова, план, заголовки и т.д.); с опорой на источники информации (картина, кинофильм, текст и т.д.); с опорой на изученную тему [1, с.79, 85]. При выполнении упражнений в качестве единицы предъявления материала, как правило, выступает высказывание или цепочка высказываний, т.е. текст.

Задачей упражнений, обучающих подготовленному монологическому высказыванию, является воспроизведение извлеченной из текста информации. Для обучения воспроизведению сообщения следует выделить две основные группы умений, которые должны быть сформированы у иностранных студентов для овладения этим видом репродуктивной деятельности:

1. умение извлекать смысловую информацию из текста, т.е. находить главное и второстепенное, ориентироваться в структуре текста.

2. умение передавать извлеченную из текста информацию вербальными средствами.

Для овладения этими умениями могут быть предложены следующие комплексы упражнений с речевой направленностью:

Упражнения для развития умений извлекать смысловую информацию из текста.

1. Определить тему текста.

2. Выделить в тексте главное и второстепенное.

3. Разделить текст на законченные смысловые от- резки.

4. Озаглавить выделенные смысловые отрезки.

5. Поставить вопросы к отдельным высказываниям.

6. Определить основную тему каждого высказывания.

7. Разбить высказывание на элементарные мысли.

8. Выделить в каждом высказывании главное.

а) в форме вопросов;

б) в форме повествовательных предложений;

в) в форме назывных предложений.

Упражнения для развития умений воспроизводить извлеченную из текста информацию.

1. Соединить выделенные «смысловые отрезки» отдельных высказываний в единое смысловое целое.

2. Пересказать кратко текст по плану, на основе заголовков (пересказ-реферат).

3. Пересказать текст подробно, развернув каждый пункт плана (в качестве ориентиров могут предлагаться ключевые слова в вопросы).

4. Составить конспект текста (полный, выборочный).

Основу обучения воспроизведению прочитанного или прослушанного сообщения составляет учебный текст. Как познавательный процесс понимания и усвоения содержания текста определяется степенью осмысления заключенной в тексте информации, что зависит не только от смысловой, структурной и языковой систем текста как источника информации, но и от соответствия уровня языкового развития воспринимающего (знания грамматики, объема словарного запаса, степени овладения значениями слов, их сочетаемостью), его системы понятий и языку текста, а также от особенностей психического состояния воспринимающего [4,5]. Следовательно, тексты, которые предназначаются для восприятия и воспроизведения заключенной в них информации, должны отвечать определенным требованиям. На наш взгляд, необходимо использовать следующие критерии их отбора:

1. тематическое и структурно-композиционное единство текста;

2. познавательная, информативная ценность текста;

3. соответствие понятийной структуры учебных текстов и их языка уровню знаний студентов по языку и специальности;

4. тематическая завершенность.

Основным моментом процесса понимания текста, определяющим его результат, является выделение в тексте смысловых опорных пунктов [7,9]. Смысловые опорные пункты обобщают в себе содержание отдельных, различных по объему частей текста, представляющих собой содержательно законченные «смысловые периоды». Именно на основе смысловых опорных пунктов 
строится внутриречевая схема текста [9], которая затем развертывается говорящим или пишущим в сообщении.

Как отмечают исследователи, мыслительная работа при восприятии научного текста включает в себя в качестве существенного звена соотнесение между собой предметов мысли, денотатов предложения, «смыслового периода» и текста в целом. Процесс осознания указанных элементов определяется их взаимозависимостью в тексте: основным является предмет мысли, денотат всего текста, им определяется предмет мысли в «смысловом периоде», а денотатов «смыслового периода» - предмет мысли в предложении. Понять речевое сообщение, текст - значит, установить, о каких предметах, явлениях и отношениях между ними в нём говорится [10].

Анализ текста начинается с выделения его темы, которая распадается на ряд подтем, каждая из которых, в свою очередь, может иметь подтемы и т.д., т.е. текстовая иерархия задаётся темой, поэтому необходимо, прежде всего, научить учащихся выделять тему всего текста, делить текст на законченные смысловые отрезки, цепь высказываний. В каждой законченной части текста-высказывания учащиеся определяют тему высказывания, формулируют его главную мысль, выделяют основное и второстепенное, выясняют смысловые связи. Соединение ключевых предложений каждого отдельного высказывания создает «смысловую перспективу» текста - краткое изложение основных моментов, наиболее значимых для данного сообщения. Такой тип пересказа текста носит название реферирующего. Реферирующий пересказ имеет большое значение для извлечения важнейших мыслей текста и готовит студентов к такому сложному виду работы, как реферирование, которое предполагает извлечение из текста в устном или письменном его предъявлении основного содержания и сообщение его в устной или письменной форме в сжатом обобщенном виде.

Деление текста на законченные высказывания - первая, главная часть упражнения в составлении плана прочитанного или прослушанного сообщения, носящая аналитический характер. Поэтому составление плана рекомендуется проводить при повторном чтении, когда содержание текста в целом уже воспринято. Озаглавливание выделенных частей текста, т.е. «свертывание» информации до смысловой вехи, запись плана и перечитывание его являются этапом синтеза [2].

Составление плана учит производить анализ и синтез, абстрагировать и обобщать, отделять главное от второстепенного и т.д. Навыки составления плана требуют умения сообщать в нескольких словах основное содержание прочитанного или прослушанного отрывка, части целого, т.е. охватывать содержание сообщения в целом.
Необходимо научить студентов составлять простой и сложный планы. Сложный план дает возможность точнее представить структуру и композицию текста. В качестве названий отдельных пунктов плана, заголовков частей текста могут выступать повествовательные предложения, часто взятые из текста, вопросительные и назывные предложения. Наиболее трудно составлять план в виде назывных предложений, так как такой план имеет обобщающий характер, предполагает наличие у студентов таких развитых умении, как сокращение, трансформация предложений.

Упражнение в составлении плана прочитанного или прослушанного сообщения играет важную организующую и регулирующую роль в, протекании устной я письменной речи, причем, как указывают психологи, особенно ценно наличие твердого, четкого, фиксированного, т.е. письменного плана, так как письменный план обычно гораздо содержательнее, детальнее и конкретнее устного.

Являясь зрительной опорой, логико-тематический план помогает учащимся точнее н полнее изложить материал, дисциплинирует мысль, приучает к последовательности в передаче фактов, развивает умение отделять главное от второстепенного, выделять основные мысли текста в их взаимосвязи. «Не столько план сам по себе, как итог наших действий или ближайший продукт их, сколько сам процесс его составления играет особенно важную роль в запоминании, оказывается весьма важной и действительной опорой запоминания» [7, c.319].

Работа над планом подготавливает учащихся к воспроизведению текста, а опора на план улучшает качество воспроизведения, его логичность, связность.

Важной опорой при воспроизведении текста являются также ключевые слова. Обычно это бывают слова, необходимые для структурного оформления речевой модели, представляющие собой любые, наиболее информативные, «рельефные» слова текста, смысловые опорные пункты высказывания [4].

Воспроизведение текста может быть различной степени свернутости. По объему содержания воспроизведение может быть полным и частичным (выборочным); по степени детализации - подробным и сжатым. Так, например, выделяются такие виды пересказа текста: пересказ, близкий к тексту сообщения, реферирующий пересказ, комментирующий пересказ.

Пересказ, близкий к тексту сообщения - очень эффективное упражнение для развития устной и письменной речи студентов, так как это упражнение даёт возмож- 
ность сосредоточить внимание на форме выражения; план содержания представлен в тексте. Пересказ, близкий к тексту, будучи менее творческим, чем другие виды пересказа, такие, как реферирующий, комментирующий и др., имеет важное значение для развития грамматически правильной, логичной речи студентов, способствует обогащению ее новыми словами и конструкциями. При пересказе, близком к тексту, учащимся дается сознательная установка на употребление в речи того языкового материала, который представлен в тексте. Такая установка способствует лучшему запоминанию и употреблению новых слов, синтаксических конструкций, всего языкового материала, имеющегося в тексте, для удержания в памяти многочисленных фактов, содержащихся в текстах, студентам разрешается использовать формальные опоры: план и ключевые слова.

Очень эффективным является такой прием работы, как одновременный устный пересказ текста всеми студентами группы с записью на диск, такое выполнение упражнения в аудитории очень экономично по времени его проведения, а также стимулирует лучшую подготовку студентов к занятиям, так, как заранее известно, что пересказывать текст будут все и одновременно.

К передаче сообщения в устной форме учащийся подготавливает также и конспектирование как один из видов изложения мыслей. Как известно, конспектирование занимает особое место среди речевых процессов, которое определяется, прежде всего, сочетанием рецептивных и продуктивных видов речевой деятельности, а также специфической обработкой и фиксацией получаемой информации, таким «свертыванием» текста, которое дает возможность (иногда через достаточно длительный промежуток времени) восстановить коммуникацию между конспектировавшим и автором текста или лектором [6]. Конспектирование печатного текста легче благодаря наличию зрительных образов слов, поэтому этот вид работы является очень ценным упражнением для закрепления языкового материала. Во время конспектирования печатного текста не надо думать о форме изложения, так как она представлена, в тексте; все внимание должно быть направлено на содержание сообщения, на извлечение информации. Кроме того, имея перед собой текст, студент может возвращаться к нему неоднократно.

Основной деятельностью обучающихся при воспроизведении текста является репродуктивно-мнемическая. При пересказе студент почти не меняет структурно-композиционный план текста и логику изложения.
Языковое же оформление имеющихся в тексте мыслей запомнить и воспроизвести без изменений невозможно, тем более что больная часть произвольного внимания учащихся при чтении и слушании текстов по научной тематике бывает направлена на извлечение точной, важной по смыслу научной информации.

Следуя этой теоретической предпосылке, при выполнении упражнений внимание студентов рекомендуется специально обращать на различные формы выражения одной и той же мысли. Предлагать упражнения на отработку возможных вариантов речевой реализации, проводить специальную работу по овладению синонимичными и синтаксическими конструкциями на базе научного стиля речи современного русского языка, отрабатывать основные операции по преобразованию, трансформации одной синтаксической конструкции в другую.

При воспроизведении сообщения студенты, поняв основное содержание, основную мысль высказывания, часто дают «свои», функционально эквивалентные формы выражения. Отсюда можно сделать вывод, что их внимание сосредоточивается на содержании текста, а не на языковой форме его выражения. Таких образом, подготовленность речи с точки зрения ее языкового оформления облегчает иностранным студентам процесс воспроизведения сложных по тематике научных текстов на неродном для них языке.

После прохождения языкового материала каждой темы учащимся предлагается на отработанном лексико-грамматическом материале составить сообщение, аналогичное тем, которые они неоднократно составляли в аудитории и дома, воспроизведя прослушанные и прочитанные тексты. Порождение собственного высказывания на заданную тему проводится с предварительной подготовкой дома необходимого для выполнения этой работы материала по специальным предметам, с привлечением материала из лекций или без предварительной подготовки, в аудитории, но с использованием некоторых наглядных пособий, схем, таблиц. Например, характеристику - описание того или иного элемента студенты дают, пользуясь таблицей периодической системы элементов Д.И. Менделеева и др.

Умение воспроизводить и интерпретировать информацию, содержащуюся в тексте, строить высказывание по аналогии с изученным текстом является важным этапом на пути к достижению конечной цели обучения студентов-иностранцев. 


\section{ЛИТЕРАТУРА}

1. Гез Н.И. Устная речь // Очерки по методике обучения немецкому языку: Для педагогических вузов. - М., 1974 - 243 с.

2. Жинкин Н.И. Механизмы речи - М., 1958. - 378 с.

3. Зинченко П.И., Ляудис П.Я., Невельский П.В. Структура процесса запоминания и переработка информации человеком. Бионика-М.: Наука, 1965. - $216 c$.

4. Клычникова 3.И. Психологические особенности непосредственного удержания и передачи речевого сообщения // Ученые записки МГПИия им. Мориса Тореза; Методика и психология обучения иностранным языкам. Т.53.-М., 1970. - 293 с.

5. Мотина Е.И. Язык и специальность: лингвометодические основы обучения русскому языку студентов-нефилологов. - М.: Русский язык, $1983-170$ с.

6. Смирнов А.А. Проблемы психологии памяти. - М.; Просвещение, 1966.- 422с.

7. Смирнов А.А. Психология запоминания. Изд-во: М.: Академия педагогических наук, $1948-330$ с.

8. Сурыгин А.И. Педагогическое проектирование системы предвузовской подготовки иностранных студентов. - СПб: Златоуст, 2001 - 128 с.

9. Соколов А.Н. Психологический анализ понимания иностранного текста // Вопросы психологии. 1960. № 5. - 246с.

10. Чистякова Г.Д. Исследование понимания текста как функции его смысловой структуры: Автореф. дис. канд.филол.наук М., 1975. - 24 .

( Гаджимирзоева Олеся Сабировна (olesya_sab@mail.ru).

Журнал «Современная наука: актуальные проблемы теории и практики»

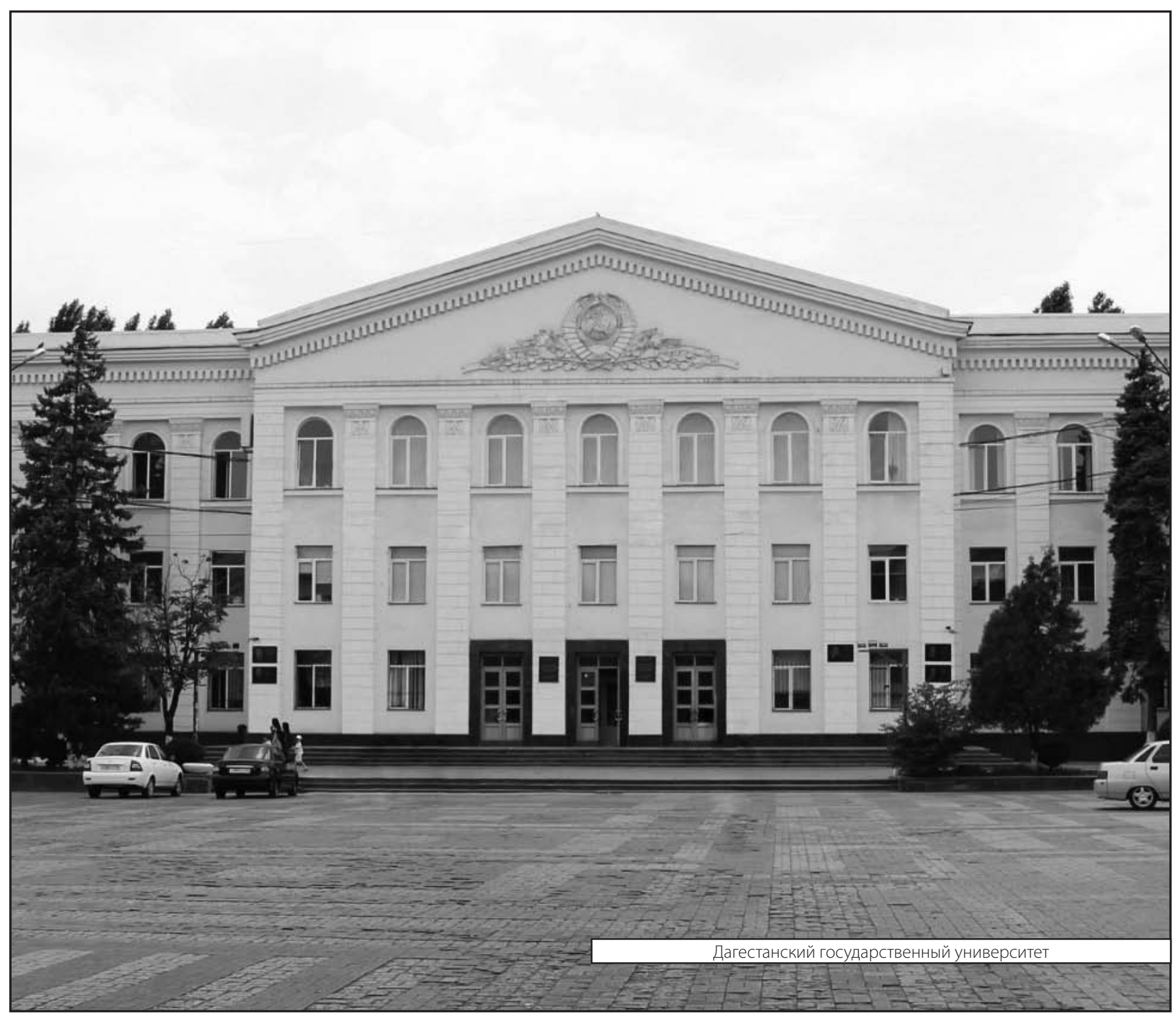

